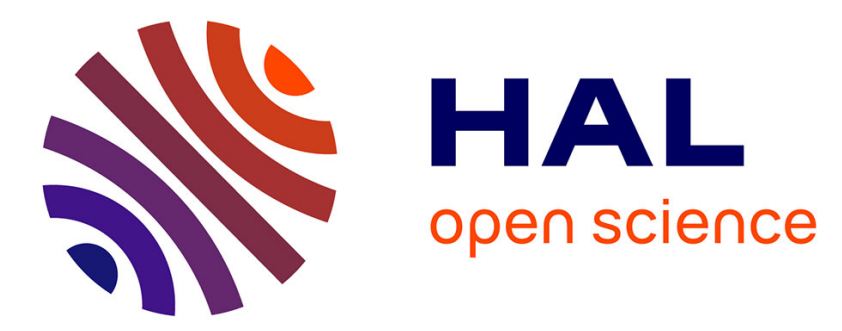

\title{
Cn to ccn relationships and cloud microphysical properties in different air masses at a free tropospheric site
}

\author{
R. Dupuy, Paolo Laj, K. Sellegri
}

\section{> To cite this version:}

R. Dupuy, Paolo Laj, K. Sellegri. Cn to ccn relationships and cloud microphysical properties in different air masses at a free tropospheric site. Atmospheric Chemistry and Physics Discussions, 2006, 6 (1), pp.879-898. hal-00327810

\section{HAL Id: hal-00327810 \\ https://hal.science/hal-00327810}

Submitted on 1 Feb 2006

HAL is a multi-disciplinary open access archive for the deposit and dissemination of scientific research documents, whether they are published or not. The documents may come from teaching and research institutions in France or abroad, or from public or private research centers.
L'archive ouverte pluridisciplinaire HAL, est destinée au dépôt et à la diffusion de documents scientifiques de niveau recherche, publiés ou non, émanant des établissements d'enseignement et de recherche français ou étrangers, des laboratoires publics ou privés. 
Cn to ccn

relationships at free

tropospheric site

R. Dupuy et al.

\section{Cn to ccn relationships and cloud microphysical properties in different air masses at a free tropospheric site}

R. Dupuy ${ }^{1, *}$, P. Laj ${ }^{1}$, and K. Sellegri ${ }^{1}$

${ }^{1}$ Laboratoire de Météorologie Physique, Observatoire de Physique du Globe de Clermont-Ferrand, CNRS UMR 6016, Université Blaise Pascal, Clermont-Ferrand, France now at: The Physics Department, NUIG, Galway, Ireland

Received: 11 October 2005 - Accepted: 12 December 2005 - Published: 1 February 2006 Correspondence to: P. Laj (laj@opgc.univ-bpclermont.fr)

(C) 2006 Author(s). This work is licensed under a Creative Commons License.

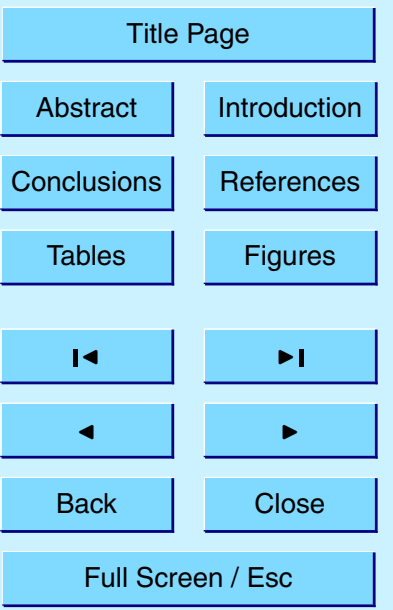

Print Version

Interactive Discussion 


\section{Abstract}

The fraction of aerosol particles activated to droplets (CCN) is often derived from semiempirical relationships that commonly tend to overestimate droplet number concentration leading to major uncertainties in global climate models. One of the difficulties

5 in relating aerosol concentration to cloud microphysics and cloud albedo lies in the necessity of working at a constant liquid water path (LWP), which is very difficult to control.

In this study we observed the relationships between aerosol number concentration $\left(\mathrm{N}_{\mathrm{CN}}\right)$, cloud droplet concentration $\left(\mathrm{N}_{d}\right)$ and effective radius $\left(\mathrm{R}_{\text {eff }}\right)$, at the Puy de Dôme 10 (France). A total of 20 cloud events were sampled representing a period of more than $250 \mathrm{~h}$ of cloud sampling. Samples are classified first according to air mass origins (Modified Marine, Continental and Polluted) and then according to their liquid water content (Thin, Medium and Thick clouds).

The CCN fraction of aerosols appears to vary significantly according to the air mass 15 origin. It is maximum for Continental air masses and minimum for Polluted air masses. Surprisingly, the CCN fraction of Modified Marine air masses fraction is lower than the continental air mass and from expected from previous studies. The limited number of activated particles in Modified Marine air masses is most likely the result of the presence of hydrophobic organic compounds. The limited activation effect leads to a 0.5 to $1 \mu \mathrm{m}$ increase in $R_{\text {eff }}$ with respect to an ideal Marine case. This is significant and implies that the $\mathrm{dR}_{\text {eff }} / \mathrm{dN}_{\mathrm{CN}}$ of low-continental clouds is higher than expected.

\section{Introduction}

Quantification of the indirect radiative forcing of aerosols on climate through a change in cloud droplet number size distributions (better known as the Twomey effect; Twomey, Genio, 1999). The present uncertainty is in the range of 0 to $-1.5 \mathrm{Wm}^{-2}$ and arises

ACPD

$6,879-898,2006$

\section{Cn to ccn relationships at free tropospheric site}

R. Dupuy et al.

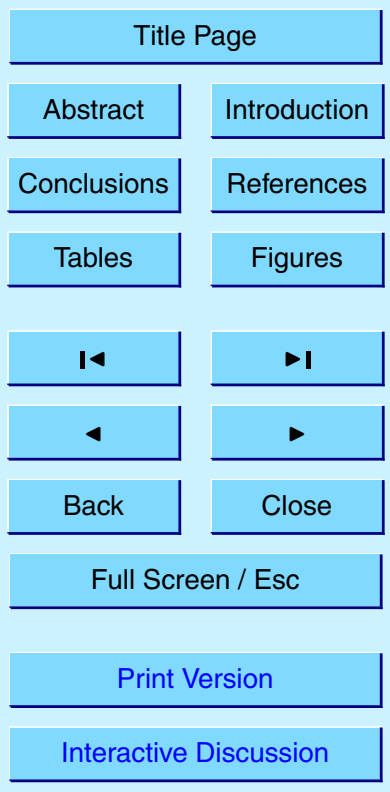

EGU 
mostly from the poor representation of cloud scale processes in GCMs (Jones et al., 1994). In particular, the fraction of aerosol particles activated to droplets (CCN) is often derived from semi-empirical relationships between aerosol (or sulphate) mass or number and cloud droplet concentration (Boucher and Lohmann, 1995) or by prognostic 5 relationships between CCN and supersaturation of water vapour (Ji and Shaw, 1998). Both approaches commonly tend to overestimate droplet number concentration (Snider and Brenguier, 2000) and do not consider possible artefacts such as the presence of soluble gases or organic material on aerosol particles (Kulmala et al., 1993; Facchini et al., 1999; Nenes et al., 2002).

10 The effect of increased aerosol concentration on cloud microphysics has been documented in a number of studies (Twohy et al., 1995; Bréon et al., 2002; Leaitch et al., 1992). However, one of the difficulties of relating observed changes in aerosol properties to changes in cloud microphysics and albedo is the implicit assumption that the liquid water path (cloud liquid water content) is constant. This assumption is very

difficult to control and is seldom verified due to feedback mechanisms affecting cloud height (Ackerman et al., 2000; Han et al., 1998). As a consequence, the ideal methodology to relate change in cloud microphysics to change in aerosol concentration implies performing observations either at constant LWP (Feingold et al., 2003) or at constant height within clouds.

\section{Measurements}

In this study we observed the relationships between aerosol number concentration $\left(\mathrm{N}_{\mathrm{CN}}\right)$ and cloud droplet effective radius $\left(\mathrm{R}_{\mathrm{eff}}\right)$, commonly used in the parameterization of cloud optical characteristics, at the Puy de Dôme cloud station (Central France, $48^{\circ} \mathrm{N}, 2^{\circ} \mathrm{E}, 1465 \mathrm{~m}$ a.s.l.) during the winter and spring 2000 and 2001 . A total of 20 cloud events were analyzed representing a period of more than $250 \mathrm{~h}$ of cloud sampling.

Measurements of total particle concentration $\left(\mathrm{N}_{C N}\right)$ were performed using a TSI 3010

\section{ACPD}

$6,879-898,2006$

\section{Cn to ccn relationships at free tropospheric site}

R. Dupuy et al.

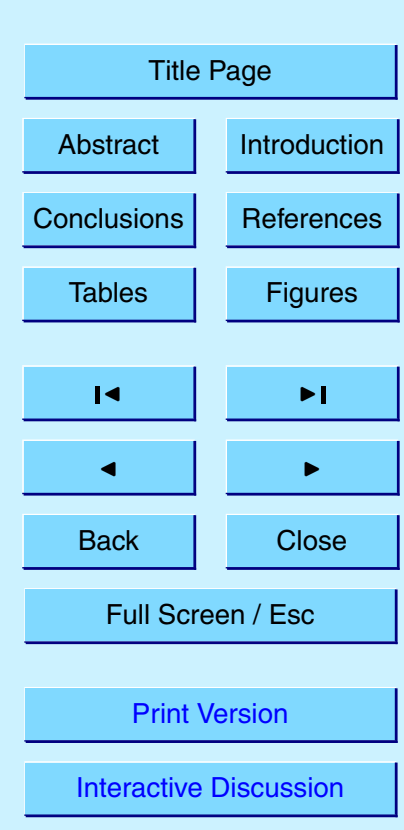

EGU 
particle counter (CPC) sampling downstream a whole air inlet. The whole air inlet has been specifically designed to allow, under cloudy conditions, the sampling of both particles and evaporated cloud droplets. The droplet number $\left(\mathrm{N}_{d}\right)$ - corresponding to the CCN number concentration $N_{C C N}$ for $L W C<0,5 \mathrm{~g} \mathrm{~m}^{-3}$ (Flossmann et al., 1985) 5 is derived from a PMS Forward Scattering Spectrometer Probe (FSSP) located inside a wind tunnel operating isocinetic conditions at $40 \mathrm{~m} \mathrm{~s}^{-1}$. The cloud droplet effective radius $\left(R_{\text {eff }}\right)$, commonly used in the parameterization of cloud optical properties (Martin et al., 1994), is computed directly from the size distribution of droplets. In addition, a particle volume monitor (PVM Gerber) provides the cloud LWC. An additional CPC 10 TSI-3010, connected to an interstitial inlet $(50 \%$ cut-off $=5 \mu \mathrm{m})$, measures unactivated interstitial aerosol concentration $\left(\mathrm{N}_{\mathrm{INT}}\right)$. All measurements are performed using a time resolution of $1 \mathrm{~Hz}$. Whole air and $\mathrm{RJI}$ inlets as well as the wind tunnel have been described previously (Schwarzenboeck et al., 2000; Sellegri et al., 2003a) and provide an adequate sampling of clouds and aerosols. A complete description of the instrumental 15 deployment at the site is provided by Sellegri et al. (2003b). The fraction of aerosols activated to CCNs in clouds $\left(\mathrm{F}_{N p}\right)$ is derived using $\mathrm{N}_{d}$ and $\mathrm{N}_{\mathrm{INT}}$ :

$F_{N p}=\frac{N_{d}}{N_{d}+N_{I N T}-\Delta N}=\frac{N_{d}}{N_{C N}}$

where $\Delta \mathrm{N}$ accounts for the fraction of droplets smaller than $5 \mu \mathrm{m}$ measured by FSSP and sampled in the RJI.

The chemical properties of aerosol particles are measured with two low pressure impactors connected to the whole air inlet. The first impactor is used for the determination of the inorganic fraction of the aerosols, the second for gravimetry, organic $(\mathrm{OC})$ and elemental (EC) carbon. In order to accumulate enough material for chemical analysis, an impactor run covers the entire duration of a cloud event. Description of the analytical procedures and results from the chemical analyses are available in Sellegri et al. $(2003 a, b)$.

\section{ACPD}

6, 879-898, 2006

\section{Cn to ccn relationships at free tropospheric site}

R. Dupuy et al.

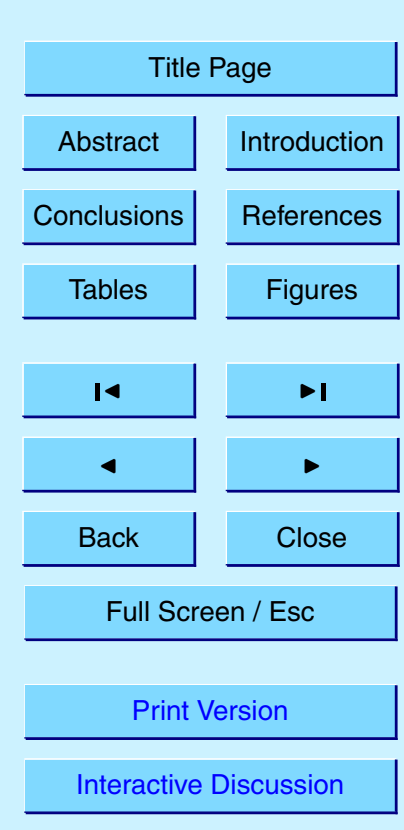

EGU 


\section{Sample classification}

Sellegri et al. (2003a) classified the air mass types at Puy de Dôme based on their aerosol mass content and analysis, and computation of back-trajectories. Based on the same cloud events than the ones studied in Sellegri et al. (2003a), and hence the 5 same air mass classification, we observed that aerosol number concentration followed this classification with Modified Marine (MM) type showing $\mathrm{N}_{\mathrm{CN}}<700 \mathrm{~cm}^{-3}$, Continental (CL) showing $700 \mathrm{~cm}^{-3}<\mathrm{N}_{\mathrm{CN}}<2200 \mathrm{~cm}^{-3}$ and Polluted (PL) showing $\mathrm{N}_{\mathrm{CN}}>2200 \mathrm{~cm}^{-3}$. Modified Marine air masses are advected to Puy de Dôme during westerly conditions (distance to the Atlantic Ocean is $500 \mathrm{~km}$ ) while continental air masses originate from 10 Northern Europe. In contrast, PL air masses correspond to specific conditions where $\mathrm{CL}$ air masses are mixed with urban plumes from the large industrial areas of Northern France and Benelux.

The bulk chemical composition of the particles for each air mass type, derived from the sum of cascade impactor stages (Sellegri et al., 2003a), is presented in Fig. 1.

15 As noticed by Sellegri et al. (2003a), the chemical composition differs according to the origin of the air masses. Modified Marine air masses are characterized by a high sea salt content, but also by a high fraction of organic material (56\%), as compared to the other two air mass types (34\% and $24 \%$ for CL and PL, respectively). Instead, polluted air masses are characterized by a higher fraction of inorganic material, and in particular $\mathrm{NO}_{3}^{-}$(22\% for PL as respect to $19 \%$ for $\mathrm{CL}$ and $7 \%$ for $\left.\mathrm{MM}\right)$.

The averaged microphysical properties of clouds (LWC and $\mathrm{R}_{\text {eff }}$ ) along with the averaged $\mathrm{N}_{\mathrm{CN}}$ and $\mathrm{F}_{\mathrm{Np}}$ for each of the air mass type are shown in Table 1. The threshold for LWC is set at $0.05 \mathrm{~g} \mathrm{~m}^{-3}$. This classification shows that FNp changes with the origin of the air mass, as expected from previous studies (Leaitch et al., 1992; Gillani (al., 1995), with maximum scavenged fraction for CL air masses and minimum for $\mathrm{PL}$ air masses. As expected, $\mathrm{F}_{\mathrm{Np}}$ is the lowest for $\mathrm{PL}$ air masses (CCN accounts for $33 \pm 11 \%$ of all particles $>10 \mathrm{~nm}$ ). Surprisingly, $F_{\mathrm{Np}}$ is larger during continental conditions $(48 \pm 16 \%)$ than during MM conditions $(42 \pm 14 \%)$. These values are in the range
ACPD

$6,879-898,2006$

\section{Cn to ccn relationships at free tropospheric site}

R. Dupuy et al.

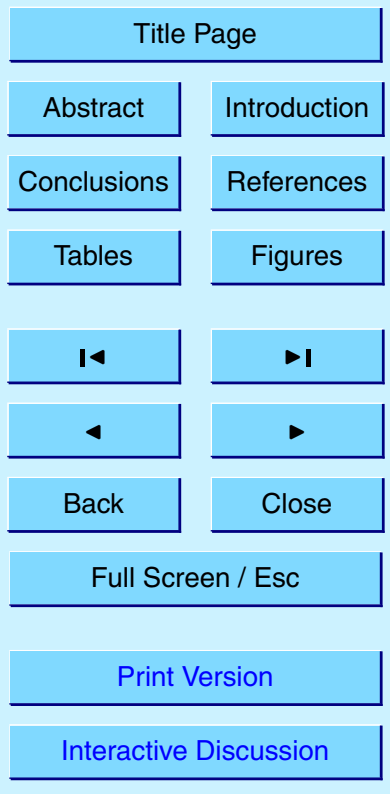

EGU 
of those measured in previous studies (Gillani et al., 1995; Martinsson et al., 2000; Chuang et al., 2000) although direct comparison is rather difficult because very few studies considered the large variety of clouds measured in this study.

However, changes in $F_{N p}$ are not only a result of particle properties because $F_{N p}$ 5 varies according to the supersaturation in cloud and therefore to the height from the cloud base. This appears in Fig. 2 where the relationship between $F_{\mathrm{Np}}$ and LWC is shown for the three air mass types. For clarity, an averaged $F_{\mathrm{Np}}$ is calculated for each $0.01 \mathrm{~g} \mathrm{~m}^{-3}$ interval of the LWC. This graph shows that $F_{N p}$ is higher for CL air masses than for both PL and MM air masses regardless of the LWC. At low LWC, $F_{\mathrm{Np}}$ 10 is rapidly changing with increasing LWC reaching a maximum for LWC ranging from 0.2 to $0.5 \mathrm{~g} \mathrm{~m}^{-3}$. A second maximum is reached for high LWC values.

In a cloud, the adiabatic lifting of droplets leads to a linear relationship between LWC and $\mathrm{h}$ (Pruppacher and Klett, 1997, and reference therein). To account for the changes in $\mathrm{F}_{\mathrm{Np}}$ with LWP, we assumed no entrainment of dry air into the cloud. This hypothesis 15 is difficult to verify without continuous monitoring of the cloud base height. The process of entrainment, however, leads to a modified droplet size distribution as respect to that produced by adiabatic lifting. The spectral shape parameter $\mathrm{k}$ can be used to assess the variability of the droplet size distribution. This parameter is defined as (Martin et al., 1994):

20 $R_{\text {eff }}^{3}=k R_{v}^{3}$

where $\mathrm{R}_{v}$ is the mean volume radius of the distribution. The spectral shape parameter is equal to unity for a monodisperse distribution. The following expression of $R_{\text {eff }}$ can be derived from Eq. (1) (Martin et al., 1994; McFarquhar and Heymsfield, 2001):

$R_{\text {eff }}=\left(\frac{3 \mathrm{LWC}}{4 \pi \rho_{w} k N_{d}}\right)^{1 / 3}$

25 If $\mathrm{k}$ is constant, then $\mathrm{R}_{\text {eff }}^{3}$ is linearly correlated to $\mathrm{LWC} / \mathrm{N}_{d}$. This is confirmed in Fig. 3 where the variations of $\mathrm{R}_{\text {eff }}^{3}$ and $\mathrm{LWC} / \mathrm{N}_{d}$ are compared for the 3 air mass categories 884

\section{ACPD}

$6,879-898,2006$

\section{Cn to ccn relationships at free tropospheric site}

R. Dupuy et al.

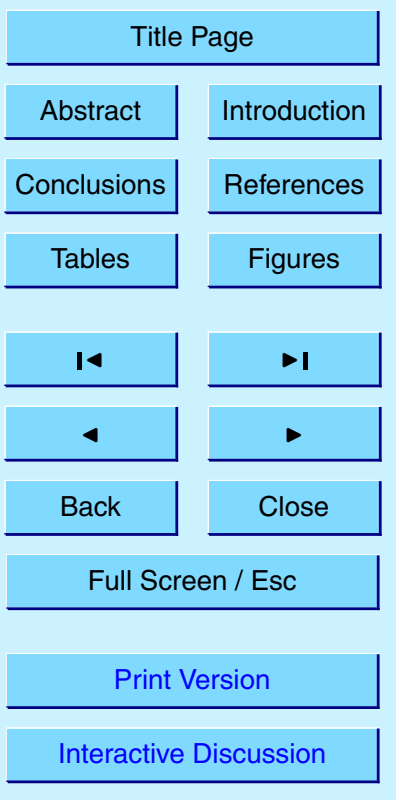

EGU 
and fitted with a linear regression. The coefficient of determination $\left(R^{2}\right)$ is higher than

0.98 for all three categories. On average, the adiabatic assumption is therefore applicable at Puy de Dôme, despite turbulences and entrainment produced by the orography. The effect of entrainment is mostly seen near cloud base (i.e. at low LWC), when both

$5 \quad F_{\mathrm{Np}}$ and $k$ show a high variability.

Under the adiabatic assumption, LWC is indicative of height from the cloud base, and we performed a second sample classification on the basis of the LWC. Three LWC classes are considered: thin clouds - sampled near the cloud base - for $\mathrm{LWC}<0.2 \mathrm{~g} \mathrm{~m}^{-3}$, medium clouds with LWC values in the range of $0.2<\mathrm{LWC}<0.4 \mathrm{~g} \mathrm{~m}^{-3}$, 10 and thick clouds where LWC $>0.4 \mathrm{~g} \mathrm{~m}^{-3}$. The two classifications with $C N$ and LWC lead to 9 different categories. Thick clouds forming in MM air masses contain the lowest number of samples, accounting for less than $1 \mathrm{~h}$ of sampling. All other categories are represented by a sampling period of more than $2 \mathrm{~h}$ which reaches $32 \mathrm{~h}$ for the most common category (medium CL).

\section{4. Analysis}

A statistical analysis of the CCN fractions for all 9 categories is presented in Fig. 4 showing large variations among categories. The computed $F_{\mathrm{Np}}$ values are statistically different (at the $99 \%$ confidence level) for each one of the categories. The average aerosol partitioning $\mathrm{F}_{\mathrm{NP}}$ is calculated for each category showing that the $\mathrm{CCN}$ fraction varies significantly with respect to both $L W C$ and $\mathrm{N}_{\mathrm{CN}}$. As expected, the classification confirms that the CCN fraction is lower for PL air masses than for $C L$ and MM air masses regardless of LWC. This is primarily resulting from the presence of a higher fraction of Aitken and ultrafine particles. Previous studies at Puy de Dôme showed that the activation diameter ranges from 50 to $100 \mathrm{~nm}$ (Gérémy et al., 2000). A large 25 fraction of the PL particles are smaller than the activation diameter leading to a limited $\mathrm{F}_{\mathrm{Np}}$.

Unexpectedly, the scavenged fraction is smaller for MM than for CL. This is not seen

\section{Cn to ccn relationships at free tropospheric site}

R. Dupuy et al.

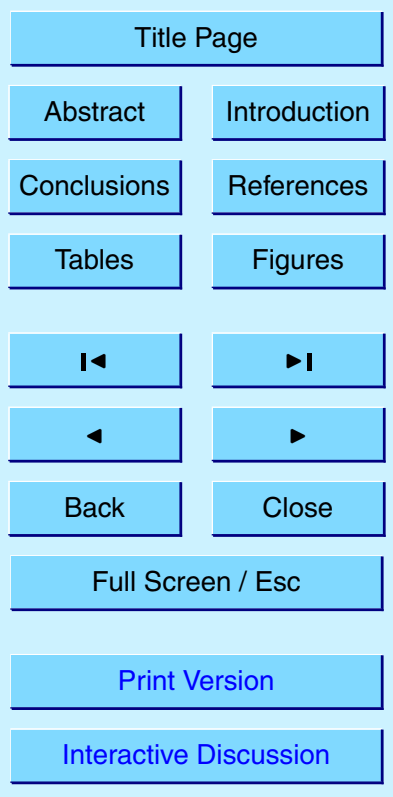

EGU 
in any previous studies (Snider and Brenguier, 2000; Gillani et al., 1995; Martinsson et al., 2000). Several hypotheses can be proposed to explain this finding: 1 - a higher activation diameter in MM air masses compared to CL air masses due to higher number of smaller particles in MM air masses compared to CL air masses, 2 - presence of ex5 ternally mixed particles, and 3 - limitation of the droplet activation due to the chemical composition of the particles.

We can exclude the first hypothesis: the particle size distribution as measured by cascade impactors shows that the fraction of accumulation-mode particles for CL and $\mathrm{PL}$ air masses is lower than for MM air masses, while the fraction of Aitken particles is 10 higher for CL and PL (Sellegri et al., 2003a). This is confirmed by more recent monitoring of the number size distribution of aerosols performed with Differential Mobility analysers. This information coupled with the fact the particle number is lower for MM than for $C L$ and $P L$, leads to the conclusion that the lower scavenged fraction during $\mathrm{MM}$ is not resulting from the aerosol size.

15 The second hypothesis (externally mixed particles) is more probable. This implies that hygroscopic marine particles are externally mixed with more hydrophobic particles. The last hypothesis is similar to the previous one except for the fact that particles are internally mixed: in both cases, hydrophobic matter would be mixed with the pure marine particles. Given the fact that the mass fraction of organic matter increases with remoteness of the air mass, it is likely that the hydrophobic particles (or their hydrophobic fraction) are (is) composed of organic material. This is consistent with Sellegri et al. (2003b) showing that, at Puy de Dôme, the organic particles are poorly scavenged in clouds.

However, the origin of the organic material during MM cases remains unclear. Recent measurements performed on the marine atmosphere revealed the presence of a large fraction of organic material (O'Dowd et al., 2004) that could explain the limited particle activation. Another hypothesis is that organic matter and/or particles are enhanced during the inland advection of marine air masses. This is consistent with the fact that the area between Puy de Dôme and the Atlantic Ocean is mostly covered by

\section{ACPD}

$6,879-898,2006$

\section{Cn to ccn relationships at free tropospheric site}

R. Dupuy et al.

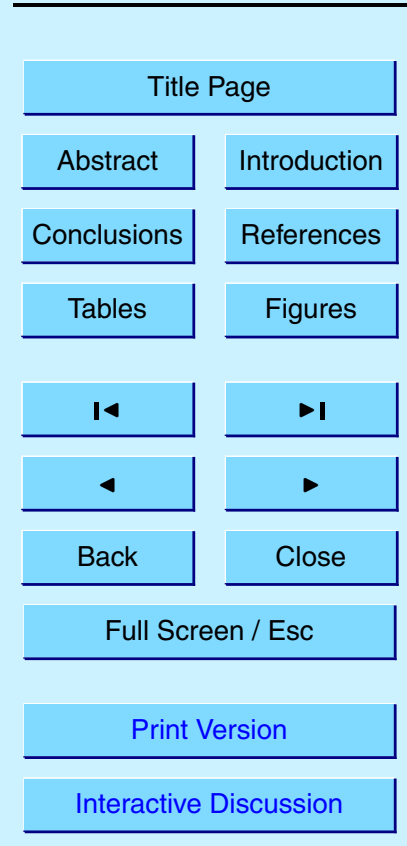

EGU 
forests and crops.

Biogenic material can either form primary particles or arise from deposition of lowvolatility organic compounds onto existing aerosol surfaces. For instance, it is known that film-forming organic compounds can alter the activation process either reducing or 5 increasing the activation diameter (Feingold and Chuang, 2003). Additional measurements, not presented in this study, show that removal of the film-forming compounds by thermo-desorption at moderate temperatures $\left(50-70^{\circ} \mathrm{C}\right)$ can either decrease or enhance the CCN fraction. However, additional studies are necessary to show the presence of an organic film onto marine particles, and identify the film-forming organic 10 species, their role in the process of particle activation and understand the mechanisms involved in the evolution of Marine aerosol inland.

\section{Impact on cloud microphysics}

The limitation of the number of particle activated during the advection of Marine air masses has direct consequences for microphysics of clouds. We can make a very crude estimate of the change in $\mathrm{R}_{\mathrm{eff}}$ resulting from the modification of the original marine air mass. Investigations of the $\mathrm{CCN}$ fraction in Marine aerosols were performed during ACE-2 (Snider and Brenguier, 2000; Bower et al., 2000; Martinsson et al., 2000). Under similar conditions as for Puy de Dôme (droplet formation forced by orography and similar supersaturation close to $1 \%$ as deduced from modelling studies at the 2

sites - Flynn et al., 2000; Gérémy et al., 2000), the CCN fraction during a cloud event corresponded to $60 \%$ of $\mathrm{N}_{\mathrm{CN}}$. The difference in $\mathrm{F}_{\mathrm{Np}}$ between Marine (ACE-2) and Modified Marine (PDD) air masses is significant, according to a Student T-test.

Such a change leads to significantly less droplets at PDD during MM air masses than expected for purely Marine air masses, and therefore a higher cloud $\mathrm{R}_{\text {eff }}$. The variations
ACPD

6, 879-898, 2006

\section{Cn to ccn relationships at free tropospheric site}

R. Dupuy et al.

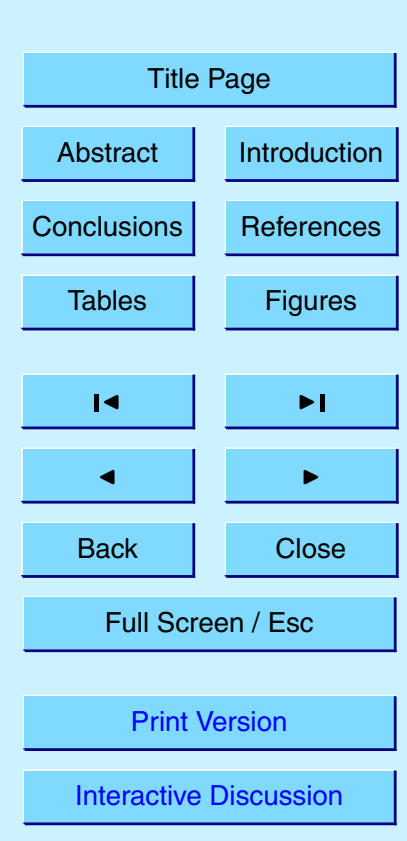

EGU 
estimate of the sensitivity of continental clouds microphysical properties to changes in aerosol number concentration. As expected, $R_{\text {eff }}$ decreases with increasing $N_{C N}$ at a rate that is close to that derived using a parameterisation proposed by Raga and Jones (1993) and corresponds, on average, to $2 \mu \mathrm{m}$ between MM and PL cases. Note 5 that the calculated $\mathrm{dR}_{\text {eff }} / \mathrm{dN}_{\mathrm{CN}}$ would have appeared much lower without the sorting of samples according to their LWC. The sensitivity of $R_{\text {eff }}$ to change in $N_{C N}\left(d R_{\text {eff }} / d N_{C N}\right)$ appears to be higher at low $\mathrm{N}_{\mathrm{CN}}$ values. This is a direct consequence of the limited fraction of particles activated in MM air masses, leading to higher $R_{\text {eff }}$ values.

In order to quantify the effect of activation limitation on cloud microphysics, we com10 pared $R_{\text {eff }}$ measured at Puy de Dôme to an estimated $R_{\text {eff }}$ for which about $60 \%$ of $C N s$ are activated to droplets $\left(F_{\mathrm{Np}}=0.6\right.$ at $\left.\mathrm{S}=1 \%\right)$ as measured for a purely marine case during the ACE-2 HILLCLOUD campaign (Bower et al., 2000). The measured and calculated $R_{\text {eff }}$ are compared at constant LWC, i.e. on the same iso-LWC lines in Fig. 5. Under this assumption, the change in $R_{\text {eff }}\left(\Delta R_{\text {eff }}\left[R_{\text {eff }}\right.\right.$ measured $-R_{\text {eff }}$ calculated]) 15 ranges from 0.5 to $1 \mu \mathrm{m}$ (Fig. 5).

\section{Conclusions}

CCN fractions have been measured at the puy de Dome cloud station for a high number of in-cloud samples, classified into three different air mass types (Marine, Continental and Polluted. Marine aerosols modified by transport over the continents appear significantly less hygroscopic than in the marine atmosphere with a CCN fraction of $42 \% \pm 14 \%$ (at supersaturation close to $1 \%$ ), to be compared with $60 \%$ for a pure Marine case, and surprisingly less than in the continental air masses $(48 \pm 16 \%)$. The limitation of the number of activated particles, and its subsequent impact on cloud microphysics, is significant. The processes leading to the hygroscopic modification of the original marine aerosol are still uncertain but are likely linked to the presence of a significant fraction of organic material. One hypothesis is that the condensation of semi-volatile organic species, possibly emitted by biogenic activity, onto the aerosol
ACPD

6, 879-898, 2006

\section{Cn to ccn relationships at free tropospheric site}

R. Dupuy et al.

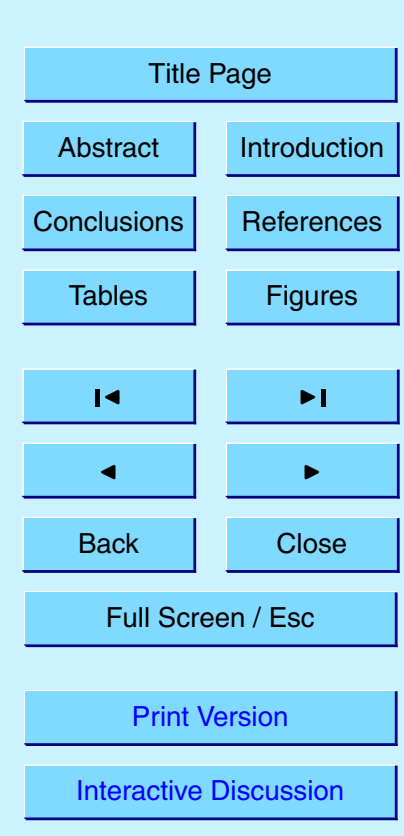

EGU 
surface limits the activation of aerosol particles in clouds. Work is in progress to confirm, or not, this hypothesis.

Compared to the theoretical Marine case, the limitation of the number of particle activated in an aged marine air mass produces an enhancement of $R_{\text {eff }}$ in clouds from 50.5 to $1 \mu \mathrm{m}$ involving, at the same time, a decrease in the cloud coverage compared to a pure marine ari mass. It is difficult to assess the regional extent of this effect until the elucidation of the nature of the chemical species involved in hygroscopic growth limitation.

Acknowledgements. Authors acknowledge financial supports from CNRS under the PNCA10 INSU program, from Ministère de la Recherche et de la Technologie under ACl-Jeune Cheurcheur to P. Laj, and ORE-BEAM, from ADEME and Ministère de l'Ecologie et du développement durable under both the PNCA (ADEME) and the PRIMEQUAL programs and from the scientific council of Région d'Auvergne. Authors wish to thank J.-L. Brenguier for useful discussion. This paper is a contribution to ACCENT Network of Excellence.

\section{References}

Ackerman, A. S., Toon, O. B., Taylor, J. P., Johnson, D. W., Hobbs, P. V., and Ferek, R. J.: Effects of Aerosols on Cloud Albedo: Evaluation of Twomey's Parameterization of Cloud Susceptibility Using Measurements of Ship Tracks, J. Atmos. Sci. 57, 16, 2684-2695, 2000.

Boucher, O. and Lohmann, U.: The sulfate-CNN-cloud albedo effect. A sensitivity study with two general circulation models, Tellus, 47B, 281-300, 1995.

Bower, K. N., Choularton, T. W., Gallagher, M. W., Beswick, K. M., Flynn, M., Allen, A. G., Davison, B. M., James, J. D., Robertson, L., Harrison, R. M., Hewitt, C. N., Cape, J. N., McFadyen, G. G., Milford, C., Sutton, M. A., Martinsson, B. G., Frank, G., Swietlicki, E., Zhou, J., Berg, O. H., Mentes, B., Papaspiropoulos, G., Hansson, H.-C., Leck, C., Kulmala, M., Aalto, P., Väkevä, M., Berner, A., Bizjak, M., Fuzzi, S., Laj, P., Facchini, M. C., Orsi, G., Ricci, L., Nielsen, M., Allan, B. J., Coe, H., McFiggans, G., Plane, J. M. C., Collett Jr., J. L., Moore, K. F., and Sherman, D. E.: ACE-2 HILLCLOUD: An Overview of the ACE-2 Ground Based Cloud Experiment, Tellus B, 52, 2, 749-777, 2000.

ACPD

$6,879-898,2006$

\section{Cn to ccn relationships at free tropospheric site}

R. Dupuy et al.

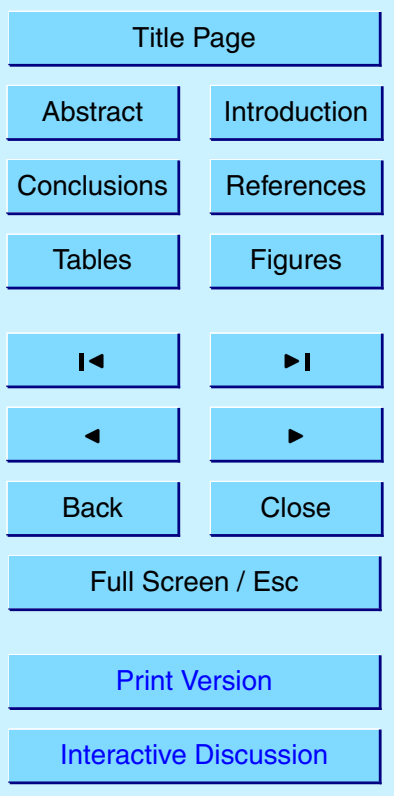

EGU 
Bréon, F.-M., Tanre, D., and Generoso, S.: Aerosol effect on cloud droplet size monitored from satellite, Science, 295, 834-838, 2002.

Chuang, P. D., Collins, D., Pawloska, H., Snider, J., Jonsson, H., Brenguier, J.-L., Flagan, R., $6,879-898,2006$ and Seinfeld, J.: CCN measurements during ACE-2 and their relationship to cloud microphysical properties, Tellus B, 52, 843-867, 2000.

Facchini, M. C, Mircea, M., Fuzzi, S., and Charlson, R. J.: Cloud albedo enhancement by surface active organic solutes in growing droplets, Nature, 401, 257-259, 2001.

Feingold, G. and Chuang, P. D.: Analysis of the influence of film-forming compounds on droplet growth: implication for cloud microphysical processes and climate, J. Atmos. Sci., 59, 2006$10 \quad 2018,2002$.

Feingold, G., Eberhard, W. L., Veron, D. E., and Previdi, M.: First measurements of the Twomey indirect effect using ground-based remote sensors, Geophys. Res. Lett., 30, 6, 20-1-20-4, 2003.

Flossmann, A. I., Hall, W. D., and Pruppacher, H. R.: A theoretical study of the wet removal of atmospheric pollutants, I: The redistribution of aerosol particles captured through nucleation and impaction scavenging by growing cloud drops., J. Atmos. Sci., 42, 83-606, 1985.

Flynn, M. J., Bower, K. N., Choularton, T. W., Wobrock, W., Mäkelä, J. M., Martinsson, B., Frank, G., Hansson, H.-C., Karlsson, H., and Laj, P.: Modelling cloud processing of aerosol during the ACE-2 Hillcloud experiment, Tellus B, 52, 2, 778-799, 2000.

20 Gérémy, G., Wobrock, W., Flossmann, A. I., Schwarzenböck, A., and Mertes, S.: A modelling study on the activation of small Aitken-mode aerosol particles during CIME 97, Tellus B, 52, 3, 959-979, 2000.

Gillani, N. V., Schwartz, S. E., Leaitch, W. R., Strapp, J. W., and Isaac, G. A.: Field observation in continental stratiform clouds: partitioning of cloud particles between droplets and unactivated interstitial aerosols, J. Geophys. Res., 100(D9), 18687-18701, 1995.

Han, Q., Rossow, W. B., Chou, J., and Welch, R. M.: Global survey of the relationships of cloud albedo and liquid water path with droplet size using ISCCP, J. Climate, 11, 1516-1528, 1998.

Intergovernmental Panel on Climate change (IPCC), climate change (2001): the scientific basis, Cambridge University Press, UK, 2001.

Ji, Q. and Shaw, G. E.: On supersaturation spectrum and size distributions of cloud condensation nuclei, Geophys. Res. Lett., 25(11), 1903-1906, 1998.

Jones, A., Roberts, D. L., and Slingo, A.: A climate model study of indirect radiative forcing by

\section{Cn to ccn relationships at free tropospheric site}

R. Dupuy et al.

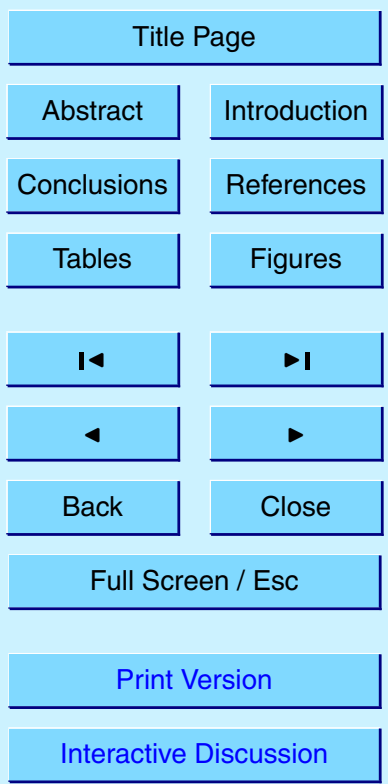

EGU 
anthropogenic aerosols, Nature, 370, 450-453, 1994.

Kulmala, M., Laaksonen, A., Korhonen, P., Vesala, T., and Ahonen, T.: The effect of atmospheric acid vapor on cloud condensation nucleus, J. Geophys. Res., 98(D12), 22 94922 958, 1993.

5 Leaitch, W. R., Isaac, G. A., Strapp, J. W., Banic, C. M., and Wiebe, H. A.: The relationship between cloud droplet concentration and anthropogenic pollution: observation and climatic implication, J. Geophys. Res., 97, 2463-2474, 1992.

Martin, G. M., Johnson, D. W., and Spice, A.: The measurement and parameterization of effective radius of droplets in warm stratocumulus clouds, J. Atmos. Sci., 51(13), 1823-1854, 1994.

Martinsson, B. G., Frank, G., Cederfelt, S.-I., Berg, O. H., Mentes, B., Papaspiropoulos, G., Swietlicki, E., Zhou, J., Flynn, M., Bower, K. N., Choularton, T. W., Mäkelä, J., Virkkula, A., and Van Dingenen, R.: Validation of very high cloud droplet number concentrations in air masses transported thousands of kilometers over the ocean, Tellus, 52B(2), 801-814, 2000.

McFarquhar, G. M. and Heymsfield, A. J.: Parameterizations of INDOEX microphysical measurements and calculations of cloud susceptibility: applications for climate studies, J. Geophys. Res., 106(D22), 28675-28698, 2001.

Nenes, A., Charlson, R. J., Facchini M.-C, Kulmala, M., Laaksonen, A., and Seinfeld, J. H.: Can chemical effects on cloud droplets number rival the first indirect effect?, Geophys. Res. Lett., 29, 17, 1848, doi:10.1029/2002GL015295, 2002.

O'Dowd, C. D., Facchini, M.-C., Cavalli, F., Ceburnis, D., Mircea, M., Decesari, S., Fuzzi, S., Yoon, Y. J., and Putaud, J.-P.: Biogenically driven organic contribution to marine aerosol, Nature, 431, 676-680, 2004.

Pruppacher, H. R. and Klett J. D.: Microphysics of clouds and precipitation, Kluwer Academic Publishers, second edition, 1997.

Raga, G. B. and Jonas, P. R.: Microphysical and radiative properties of small cumulus clouds over the sea, Quart. J. Roy. Meteor. Soc., 119, 1399-1417, 1993.

Schwarzenböck, A., Heintzenberg, J., and Mertes, S.: Incorporation of aerosol particles between 25 and $850 \mathrm{~nm}$ into cloud elements: measurements with a new complementary sampling system, Atmos. Res., 52, 4, 241-260, 2000.

Sellegri, K., Laj, P., Peron, F., Dupuy, R., Legrand, M., Preunkert, S., Putaud, J.-P., Cachier, H., and Ghermandi, G.: Mass balance of free trospopheric aerosol at the Puy de Dôme (France)

\section{ACPD}

6, 879-898, 2006

\section{Cn to ccn relationships at free tropospheric site}

R. Dupuy et al.

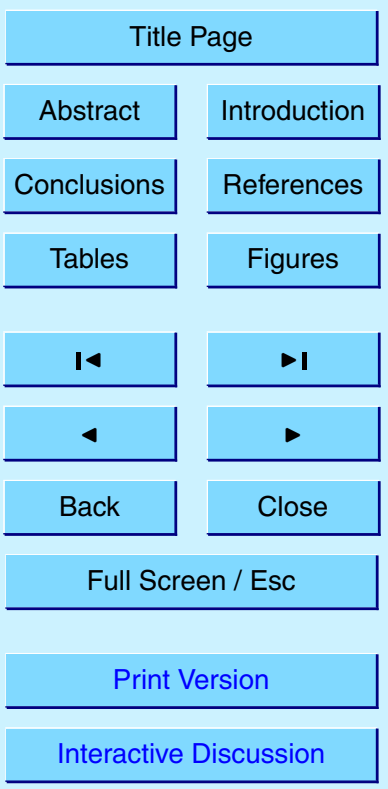

EGU 
in winter, J. Geophys. Res., 108(D11), 4333, doi:10.1029/2002JD002747, 2003a.

Sellegri, K., Laj, P., Dupuy, R., Legrand, M., Preunkert, S., Putaud, J.-P., and Cachier, H.: Size-dependent scavenging efficiencies of multi-component atmospheric aerosols in clouds. J. Geophys. Res., 108(D11), 4334, doi:10.1029/2002JD002749, 2003b.

5 Snider, J. R. and Brenguier, J. L.: A comparison of cloud condensation nuclei and cloud droplet measurements obtained during ACE-2, Tellus, 52B, 827-841, 2000.

Twohy, C. H., Durkee, P. A., Huebert, R. J., and Charlson, R. J.: Effects of aerosols particles on the microphysics of coastal stratiform clouds, J. climate, 8, 773-783, 1995.

Twomey, S.: Aerosol, clouds and radiation, Atmos. Envir., 24A(11), 2435-2442, 1991.

10 Yao, M. S. and DelGenio, A. D.: Effect of cloud parameterization on the simulation of climate changes in the GISS GCM, J. Climate, 12, 761-779, 1999.

\section{ACPD}

$6,879-898,2006$

Cn to cen relationships at free tropospheric site

R. Dupuy et al.

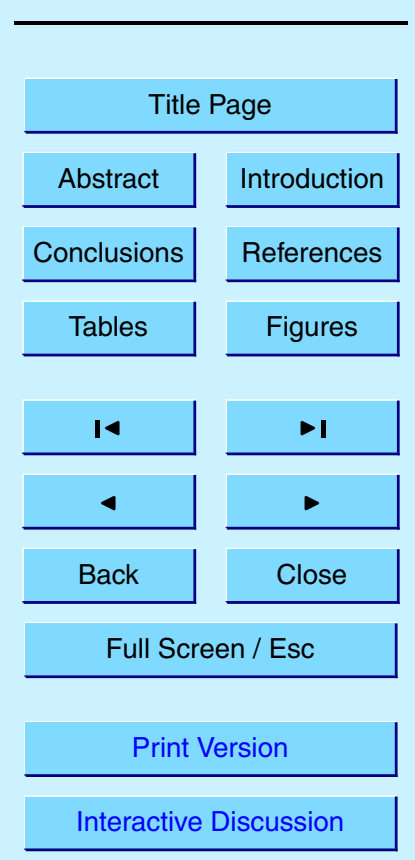




\section{ACPD}

$6,879-898,2006$

\section{Cn to ccn}

relationships at free tropospheric site

R. Dupuy et al.

Table 1. Averaged values of cloud liquid water content, particle concentration $\left(\mathrm{N}_{\mathrm{CN}}\right)$, scavenged aerosol fraction $\left(\mathrm{F}_{\mathrm{Np}}\right)$ and Effective radius $(\mathrm{Re})$ for the 3 air mass categories identified at Puy de Dôme. The uncertainties correspond to one standard deviation of the mean.

\begin{tabular}{ccccc}
\hline Air mass category & $\mathrm{LWC}\left(\mathrm{g} \mathrm{m}^{-3}\right)$ & $\mathrm{N}_{\mathrm{CN}}\left(\mathrm{cm}^{-3}\right)$ & $\mathrm{F}_{\mathrm{Np}}$ & $\mathrm{R}_{\text {eff }}(\mu \mathrm{m})$ \\
\hline Modified Marine & $0.14 \pm 0.07$ & $525 \pm 103$ & $0.42 \pm 0.14$ & $6.15 \pm 1.06$ \\
Continental & $0.16 \pm 0.07$ & $1264 \pm 374$ & $0.48 \pm 0.16$ & $4.61 \pm 0.80$ \\
Polluted & $0.26 \pm 0.15$ & $3094 \pm 916$ & $0.33 \pm 0.11$ & $4.41 \pm 1.01$
\end{tabular}

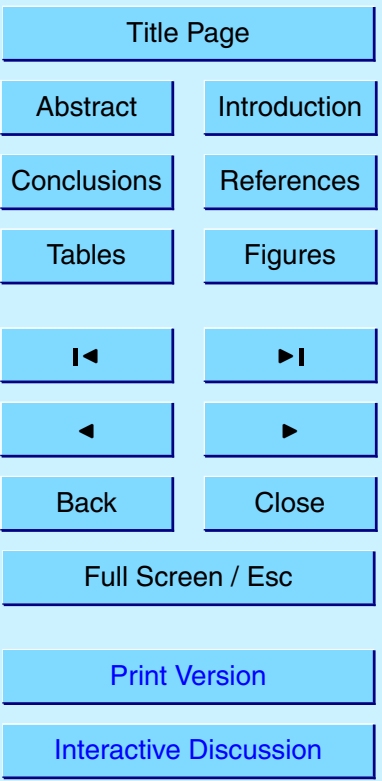

EGU 

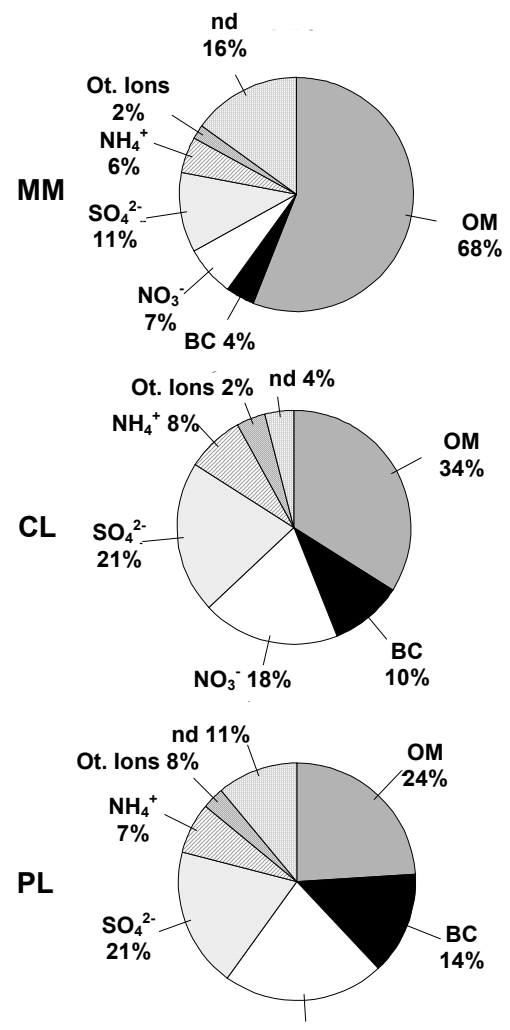

$\mathrm{NO}_{3}{ }^{-} 22 \%$

\section{ACPD}

6, 879-898, 2006

Cn to ccn

relationships at free tropospheric site

R. Dupuy et al.

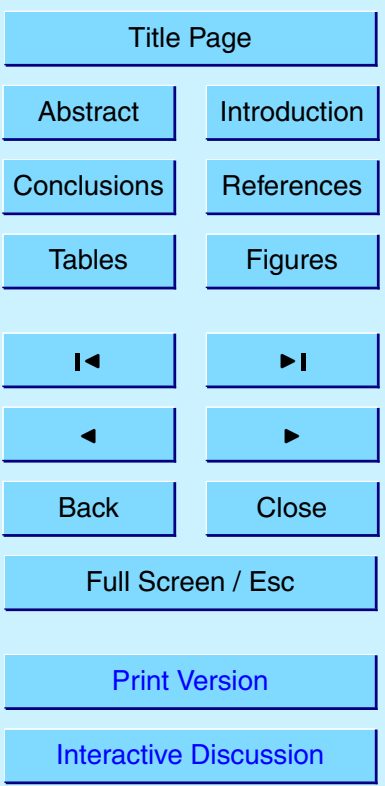

EGU 


\section{ACPD}

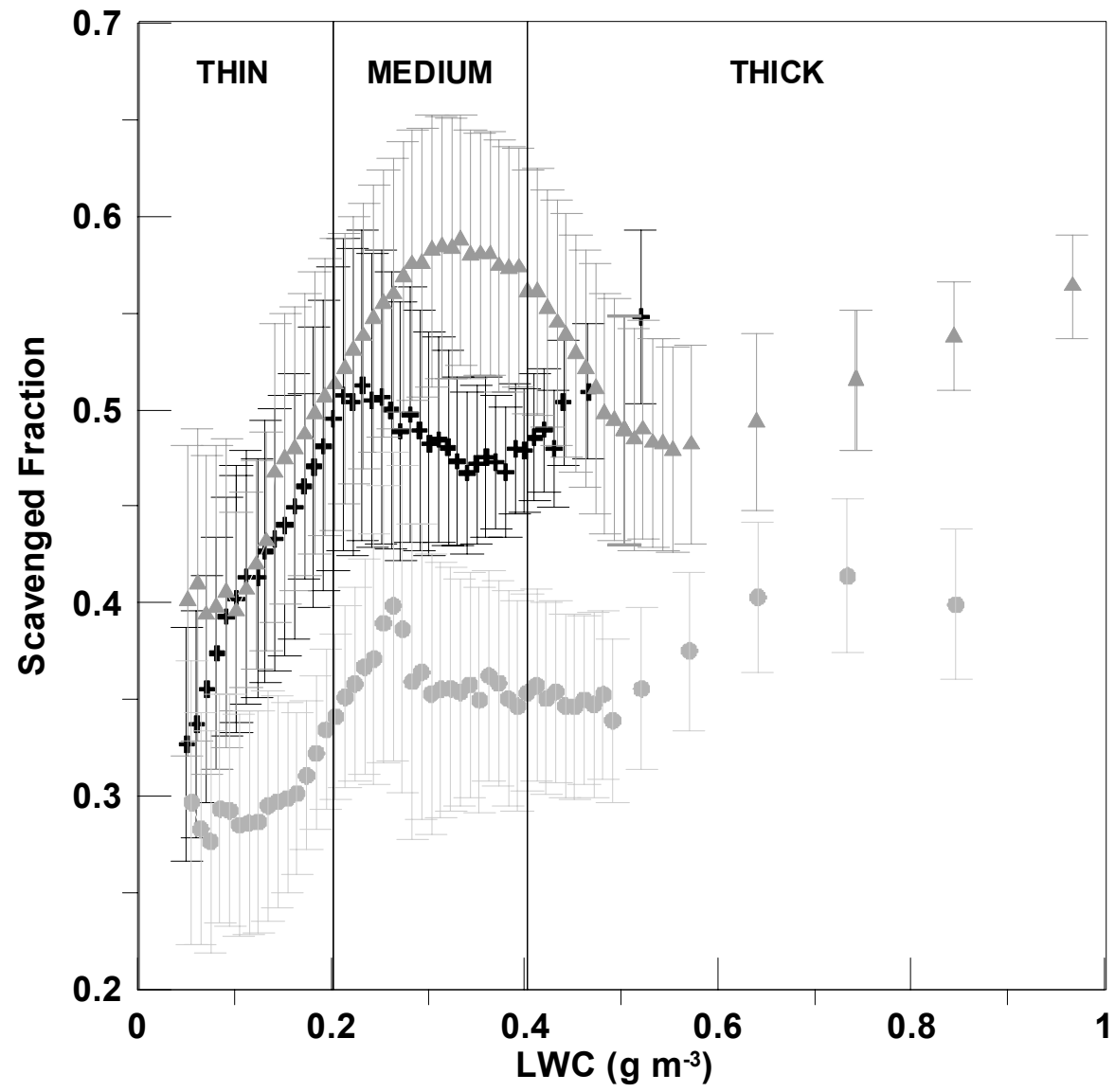

$6,879-898,2006$

Cn to ccn relationships at free tropospheric site

R. Dupuy et al.

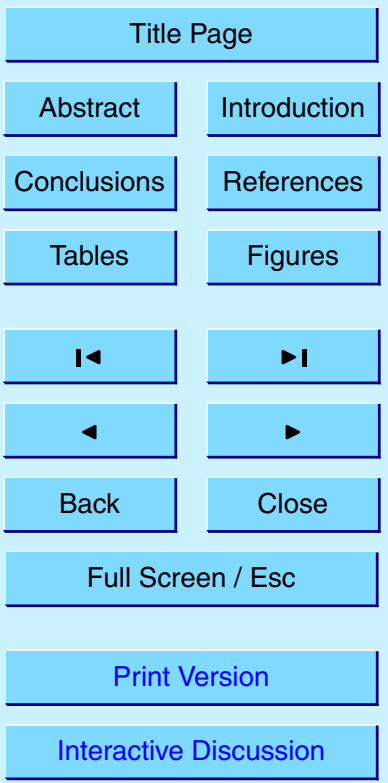

Fig. 2. Variations of the scavenged fraction of $N_{C N}$ as a function of cloud LWC for the 3 air Interactive Discussion masses MM (cross), CL (triangle) and PL (circle) Each point represents the average $\mathrm{N}_{C N}$ value 


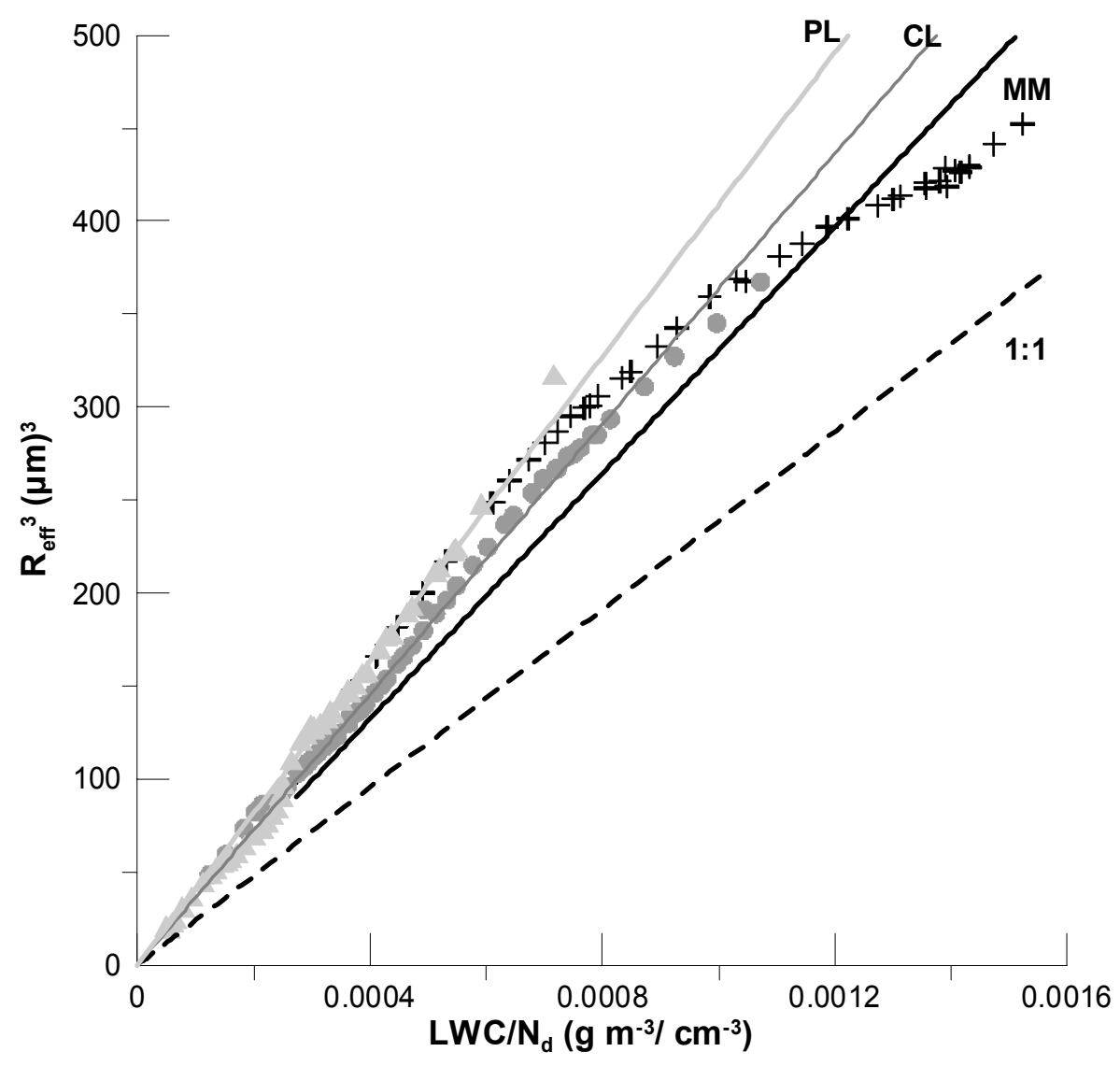

Fig. 3. Variations of $R_{\text {eff }}^{3}$ as a function of $L W C / N_{d}$ for each of the three air mass type $M M$ (cross), CL (circle) and PL (triangle). Each population is fitted with a linear regression. Each point represents the average $\mathrm{N}_{\mathrm{CN}}$ value in a $0.01 \mathrm{~g} \mathrm{~m}^{-3}$ interval of the LWC. The solid black line shows 1:1 correspondence for monodisperse size distribution where $R_{\text {eff }}=R_{v}$.

\section{ACPD}

$6,879-898,2006$

Cn to ccn relationships at free tropospheric site

R. Dupuy et al.

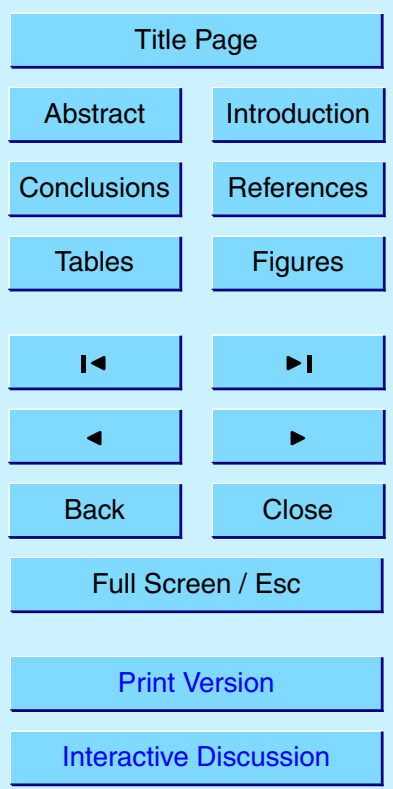

EGU 


\section{ACPD}

$6,879-898,2006$

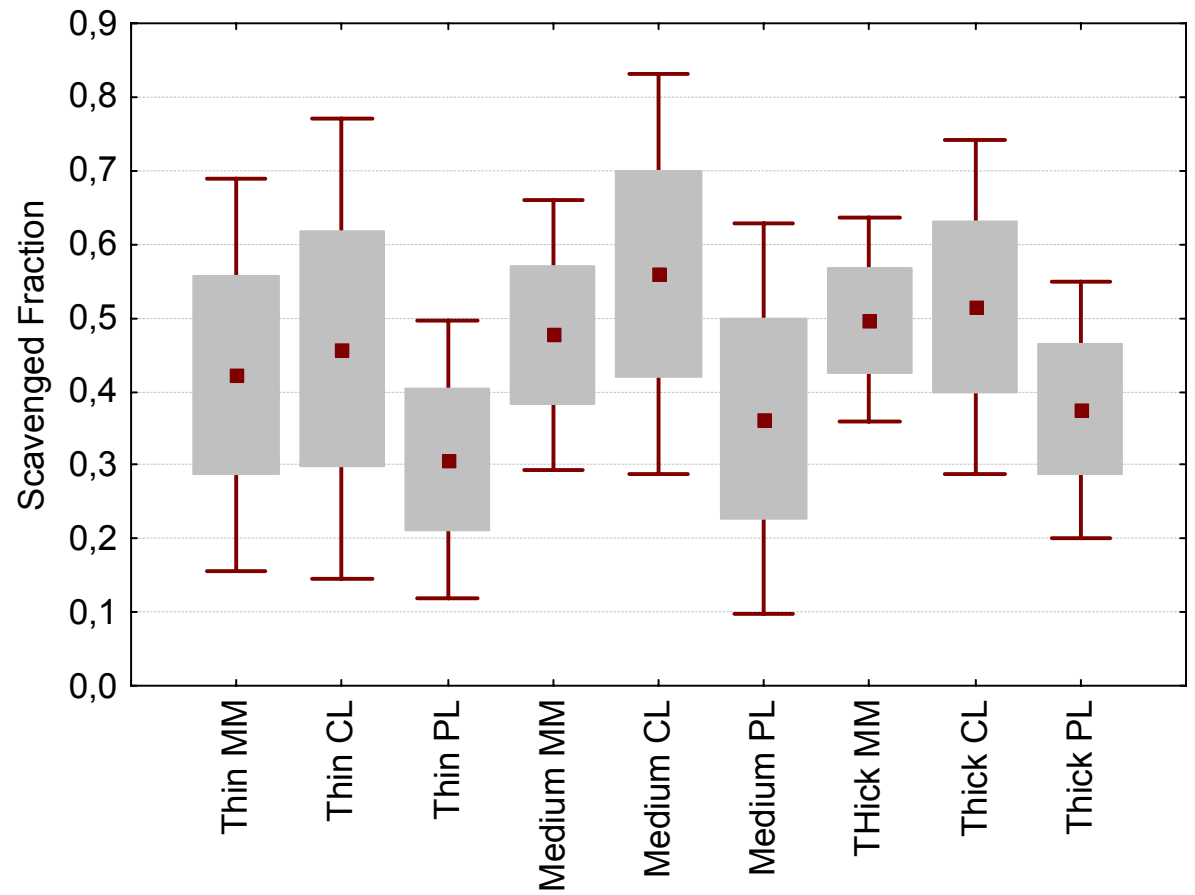

Cn to ccn relationships at free tropospheric site

R. Dupuy et al.

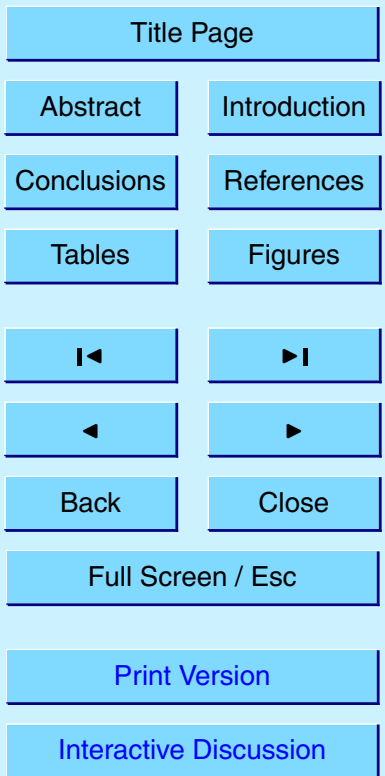

Fig. 4. Statistical analysis of the CCN fraction for the 9 classes of samples showing mean of the population, 1 standard deviation (box) and 1.96 standard deviations (whiskers), respectively. Modified Marine (1), Continental (2) and Polluted (3) and thin (A), medium-thin (B), medium- 


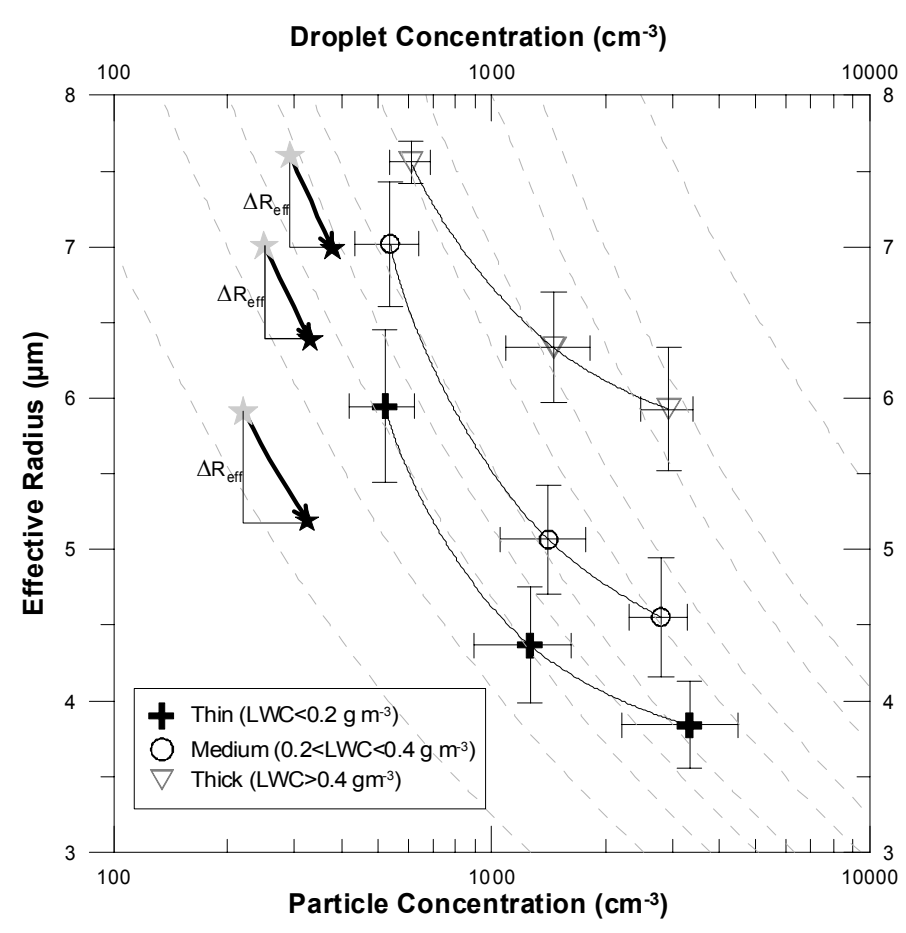

Fig. 5. Variations of $R_{\text {eff }}$ as a function of $\mathrm{N}_{\mathrm{CN}}$ concentration for the 3 classes of air mass types - Modified Marine $\left(\mathrm{N}_{\mathrm{CN}}<700\right)$, Continental $\left(700<\mathrm{N}_{\mathrm{CN}}<2200\right)$ and Polluted $\left(\mathrm{N}_{C N}>2200\right)$ - and at the 3 different range of LWC corresponding to thin (cross), medium-thin (circle), and thick (triangle) clouds. Iso-LWCs are fitted with a spline function. Grey lines are the relationship between $R_{\text {eff }}$ and $N_{d}$ at constant LWC for LWC varying from $0.05 \mathrm{mg} \mathrm{m}^{-3}$ to $2 \mathrm{mg} \mathrm{m}^{-3}$. Grey Stars on arrow start correspond to the number of droplets measured in the marine cases while Black Stars on arrow end correspond to number of droplets calculated in the purely marine cases assuming $F_{N p}=0.6$. The $D R_{\text {eff }}$ is the difference of $R_{\text {eff }}$ between measured $R_{\text {eff }}$ and a theoretical purely marine case (see text for details).
ACPD

$6,879-898,2006$

\section{Cn to ccn relationships at free tropospheric site}

R. Dupuy et al.

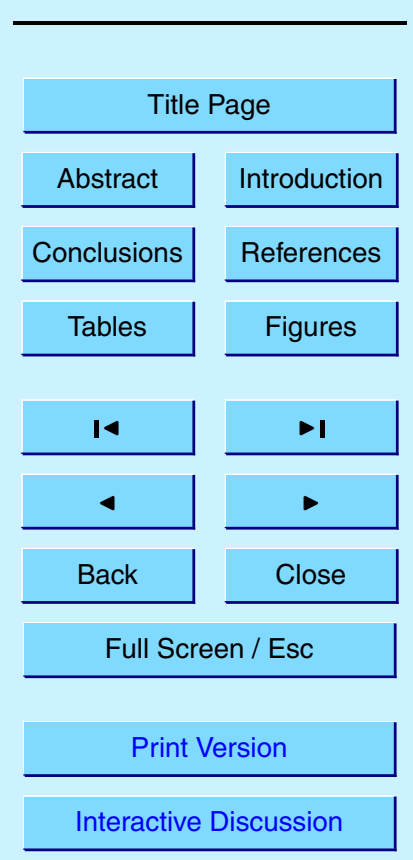

EGU 